\title{
PUNTA DE RIELES, DE MANUEL ROJAS: MONTAJE IRÓNICO DE UN ENCUENTRO ENTRE MUNDOS
}

\author{
Ana M. Lea-Plaza ${ }^{1}$ \\ Universidad Alberto Hurtado, Santiago de Chile, Chile \\ analeaplaza@gmail.com
}

\section{RESUMEN / ABSTRACT}

Punta de rieles (1959) es una novela sobre el encuentro entre dos mundos. Entre un miembro de la élite tradicional y un miembro del bajo pueblo en vías de proletarización, ambos presentados bajo la forma de dos sujetos en crisis. Este encuentro es, por lo tanto, un montaje que no deja de ser irónico; una idea técnica que va más allá de lo literario y busca referirse, sintéticamente, a un período crucial de la historia de Chile (la crisis de 1929) para reflexionar sobre las relaciones de clase que el país ha forjado hasta este momento y preguntarse por las nuevas relaciones que la crisis y el tránsito hacia la industrialización prometen. El texto que aquí se presenta busca revelar las raíces de esta problemática y de los actores involucrados; y mostrar cómo ella funciona y es tensionada en Punta de rieles. Todo ello, con el objetivo prioritario de estudiar esta obra injustamente descuidada por la crítica, buscando hacernos cargo de su complejidad discursiva y de su génesis dentro de la novelística del gran narrador chileno.

Palabras Clave: narrativa chilena, novela de formación de vanguardia, Manuel Rojas, relaciones de clase.

Punta de Rieles, by Manuel Rojas: ironic montage

OF AN ENCOUNTER BETWEEN WORLDS

Punta de rieles (1959) is a novel about the encounter between two worlds. Between a member of the traditional elite and a member of the common people in the process of proletarianization, both presented in the form of two subjects in crisis. This meeting is, therefore, an assembly not without irony; a technical idea that goes beyond the literary and seeks to address,

1 Este artículo fue elaborado en el marco del Fondecyt Postdoctoral 2016, "Formación y discurso en el Bildungsroman chileno y brasileño de vanguardia”, número 3160189. 
synthetically, a crucial period in the history of Chile (the crisis of 1929) to reflect on the class relations that the country has built up to this moment and wonder the new relationships that the crisis and the transition towards industrialization promise. The text presented here seeks to reveal the roots of this problem and stakeholders; and show how it works and is stressed in Punta de rieles. All this, with the primary objective of studying this unjustly neglected work, looking to take charge of his discursive complexity and its genesis within the fiction of the great Chilean narrator.

KEYWORDS: Chilean narrative, avant-garde Bildungsroman, Manuel Rojas, class relations.

Recepción: 14/10/2016

Aprobación: 03/04/2017

\section{INTRODUCCIÓN}

Punta de rieles (1959) es la cuarta novela de Manuel Rojas y constituye una verdadera excepción dentro de su narrativa, tanto por su forma, como por algunos aspectos esenciales de su contenido. En primer lugar, esta novela, junto con Lanchas en la bahía (1932) y La ciudad de los césares (1936), no hace parte de la tetralogía de Aniceto Hevia ${ }^{2}$, aunque mantenga con ella diversos puntos de continuidad temática. En segundo lugar, a pesar de que a partir de Hijo de ladrón ya podemos hablar de vanguardia en Manuel Rojas, con Punta de rieles esto se hace aún más evidente, pues vemos un uso explícito de la retórica experimental de ese período. Inspirado en Wild Palms, de William Faulkner, en ella encontramos un montaje de dos historias, que conforman una variante única de Bildungsroman. Por último, entre las páginas de esta obra veremos, de forma excepcional, la presencia de un nuevo sujeto social, antes ausente de su universo narrativo. Nos referimos a Fernando Larraín Sanfuentes, miembro de la decadente élite chilena de la primera mitad del siglo XX.

El texto se estructura como una novela de encuentro entre mundos. Entre un miembro de la élite tradicional y un miembro del bajo pueblo en vías de proletarización, ambos presentados bajo la forma de dos sujetos en crisis: el burgués desclasado y el criminal. El autor reúne a estos dos personajes en un espacio-tiempo determinado: una salitrera en la Antofagasta de la década de 1920 e inicios de 1930, es decir, en un período crucial de la historia de Chile, ya que se ha puesto en marcha una crisis en tres sentidos: una crisis 
financiera internacional que, a su vez, repercute en el plano económico nacional, durante la dictadura del General Ibañez del Campo, tiempos de crisis también política ${ }^{3}$.

Al contextualizar el encuentro entre Fernando Larraín Sanfuentes y Romilio Llanca en este espacio-tiempo determinado, la novela parece dialogar con un hecho específico de este periodo histórico: la reformulación de las relaciones entre las diferentes clases sociales del país en curso durante esta fase $^{4}$. En función de eso, el autor elabora una situación ficcional compuesta por técnicas literarias y estrategias retóricas que, reunidas, componen una narración drásticamente irónica. Por un lado, mostrará las relaciones entre estos dos personajes desde un punto de vista que intentará sobrepasar las relaciones de clase, desplegando una visión más humana del burgués y del

3 En relación con el ámbito económico internacional, estamos pensando en la caída de Wall Street, en Nueva York, cataclismo que agravó la crisis económica nacional de Chile durante los años treinta, generada como consecuencia de la interrupción de dos actividades que habían sido cruciales para el desarrollo del país durante por lo menos treinta años. Nos referimos, específicamente, a la industria minera y al crédito internacional. Se trata, pues, de la exportación de productos primarios, los nitratos y el cobre, y de las importaciones de capital, crédito e inversión exterior; ambas destinadas a alimentar el desarrollo general del país. La catástrofe ocasionada debido a la dependencia que el país tenía de estas actividades de comercio exterior, detonó la crisis también política en la que Chile entró durante esos años. La Gran Depresión afectó lo que se consideraba uno de los pilares del gobierno de Carlos Ibañez del Campo, es decir, la reactivación económico-administrativa, luego del conflictivo período parlamentario y de la polémica presidencia de Alessandri. Ibañez, en efecto, dio a Chile un período de cuatro años de cierta prosperidad, con la cual se justificó la limitación de las libertades. Sin embargo, cuando la gran Depresión desarmó aquello que soportaba la tolerancia al autoritarismo de Ibañez, se produjo un proceso recíproco en que, por un lado, las medidas del dictador se tornaban impopulares, al tiempo que se intensificaban las reacciones autoritarias (Bethel 1990, cap. 7).

$4 \quad$ La década de 1930 forma parte de un período de transición entre el Chile oligárquico y el mesocrático. De un régimen político-económico controlado por una clase alta interesada en sí misma y en unos pocos grupos familiares, se comienza a avanzar, a partir de 1920, hacia una rectificación de estas condiciones a través de la "ampliación de las bases sociales del Estado, que estaba dando legitimidad a la participación de los grupos medios y comenzaba a permitir la conciencia de sus derechos a las clases bajas (De Ramón 2003, p. 120). A pesar de no haber conseguido quebrar con la oposición parlamentaria, a fin de implementar las reformas sociales a favor de estas clases sociales (De Ramón, p. 124), figura emblemática de esta transformación fue el presidente Arturo Alessandri. Su actividad reformadora se completó durante el gobierno de Ibañez (De Ramón, p. 118) y permitió avanzar hacia la desintegración del Chile oligárquico, instalado en el país desde la revolución de 1891 que, con el triunfo del Congreso, entregó el control total del país a este grupo, junto con el sistema parlamentario. 
criminal, dirigida a revelar las continuidades que existen entre ambos. Por otro lado, sin embargo, aunque sin anular totalmente la perspectiva anterior, las propias técnicas y estrategias retóricas, así como la solución que Manuel Rojas otorga al enredo, se orientarán a mostrar la permanencia de estas relaciones de clase tradicionales.

\section{GÉNESIS DE PUNTA DE RIELES}

Antes de entrar en el análisis pormenorizado de cómo estos elementos se despliegan en Punta de rieles, nos gustaría introducir esta novela haciendo el esfuerzo de integrarla dentro de la obra total de Rojas, para lo que vale la pena abordarla como una novela compuesta por tres nouvelles, cada una de las cuales se conecta con un punto distinto de su trayectoria narrativa.

La primera nouvelle que consideramos necesario distinguir es la que podríamos llamar "nouvelle de formación ${ }^{5}$ de personaje subalterno", en

5 Al afirmar que Punta de rieles es una Bildungsroman, lo hacemos a partir de una comprensión histórica del género, según la cual no existe uno, sino varios Bildungsromane que van surgiendo y transformándose de acuerdo con los diferentes contextos de su aparición. Comprender Punta de rieles como formando parte de este género nos obliga a trabajar fuera de la definición conservadora y canonista que, habiéndose perfilado con Blackenburg (en 1774) durante la articulación de su teoría de la novela, y después con Körner y Morgenstern (entre 1803 y 1804), se diseminó con Dilthey durante el período de la unificación alemana y la crítica nacionalista (1870), transformándose en el locus clásico de la definición de Bildungsroman. Según esa definición conservadora, el Bildungsroman sería un tipo de romance culto, orientado a fines superiores y no de divertimento, mediante el retrato del crecimiento psicológico de su protagonista (Blackenburg), un "bello hombre" (Körner), que va tomando forma gradualmente a partir de la interacción entre sus predisposiciones naturales y las circunstancias externas con las que entra en contacto hasta alcanzar un estado armónico de perfecto equilibrio y libertad (Kontje 1993, p. 11). El recorrido de este bello hombre describiría, así, un recorrido ejemplar y representativo, capaz no solo de mostrar la formación de su protagonista, sino también de inducir la educación del propio lector. Sin embargo, como lo demuestra Todd Kontje, en el libro The German Bildungsroman: History of a National Genre, esa definición esencialista, ingenua, canonista, germanista y didáctica, la verdad corresponde a una definición dentro de una tradición crítica específica revisada y transformada a lo largo de los años, mediante nuevas interpretaciones del Wilhelm Meister, y también, mediante la aparición de otros Bildungsromane y de la apropiación del tema por parte de diferentes escuelas críticas. En su conjunto, esas circunstancias, obras y autores han ido históricamente "formando la novela de formación". El crítico alemán llega a presentar doce definiciones de Bildungsroman, comenzando por la definición de Schiller, Schlegel y Novalis, que cuestionó dicho dogma durante el primer 
que se narra la historia del obrero sindicalista que llega al escritorio de Fernando Larraín Sanfuentes ${ }^{6}$. Por el período en que está ambientada (fines de los años veinte, inicios del treinta), por el tipo de personaje que tiene por protagonista (un sujeto subalterno que comienza siendo artesano gremialista, pero que termina como obrero y dirigente sindical en una salitrera de Antofagasta) y por la temática amorosa frustrada que lo compone, esta novela se conecta con lo que Grínor Rojo distingue como la segunda etapa de la tetralogía de Aniceto Hevia. Aquella etapa comprende el periodo de formación de Aniceto y Manuel Rojas que comienza a finales de los años veinte y que corresponde, según el crítico chileno, a lo que sería "el futuro del mal cálculo" o el de la "integración burguesa frustrada" que, dentro de la tetralogía, aparece elaborado por la novela Mejor que el vino, escrita un año antes que Punta de rieles.

El personaje correspondiente a Aniceto Hevia, en el caso de Punta de rieles, pasa a llamarse Romilio Llanca, realizando un intento de integración adulta mediante una asfixiante historia de amor con Rosa, mujer con la cual

romanticismo, al detectar en la obra de Goethe un fondo irónico dentro de ese cuadro armónico analizado por la crítica nacionalista. Si la primera línea de intérpretes culminó con la crítica fascista, que quiso acentuar, una vez más, el carácter profundamente alemán del género, esta segunda fue muy importante para los comentadores de postguerra y los estudios recientes más relevantes sobre el Bildungsroman. En conclusión, para trabajar la novela de formación no necesitamos hacerlo con referencia a Los años de aprendizaje de Wilhelm Meister, ni a la definición clásica que se articula a partir de la cuestión de la integración-desintegración del héroe en la sociedad burguesa. Particularmente, nosotros proponemos que el interés central del Bildungsroman consiste en pensar la cuestión de la inserción social, pero en función de otro elemento, que le es más fundamental: la formación, instancia que es la gran búsqueda del Bildungsroman y para cuya consecución cada autor propondrá su propio camino. En el caso de Rojas, esta formación se realizará, como veremos, en las instancias que permitan realizar su ideología anarquista.

${ }^{6} \quad$ El material autobiográfico que lo ayudaría a configurar el ambiente y la familia de Romilio Llanca se lo dio fundamentalmente el pueblecito de Cáhuil, lugar que Rojas conocía en detalle, pues había veraneado allí durante varios años con su esposa María Baeza y sus hijos. Sin señalar a la persona específica en que se inspiró, Rojas extrae a su personaje de este medio que, según señala en su Antología autobiográfica (Rojas 1962, pp. 239-240) pasó a simbolizar una suerte de "patria chica" para él, dada la gran cantidad de gente proveniente de allí que conoció durante su vida.

Esta se extiende "desde los años veinte hasta los cincuenta. El factor de integración es, en cada uno de los tres intentos que Aniceto realiza para ello, una mujer (...) Por diferentes razones, esas relaciones amorosas del Aniceto "maduro" (y el proyecto que ellas conllevan) fracasan (Rojo 2009, p. 24). 
comparte una anómala vida sexual, económica y, podría decirse, familiar, en el escenario de las salitreras chilenas, territorio industrial dentro del cual Llanca, antiguo artesano, comienza a trabajar. Todo eso sucede luego de un largo proceso formativo que podría conectarse con lo que Rojo distingue como la etapa más importante en la tetralogía de Aniceto Hevia. Dicha etapa consta de dos momentos, también presentes en la biografía de Romilio Llanca. El primero de ellos es denominado por Grínor Rojo como "la edad de la inocencia"8, y corresponde a la etapa en que Aniceto da sus primeros pasos en el mundo hasta que conoce a Cristián y al Filósofo, en Hijo de ladrón. El segundo, denominado por el mismo crítico como "edad del vagabundaje programático", se inicia cuando, después de la separación del trío de El Membrillo, Aniceto, ahora anarquista, inicia su búsqueda de un destino no burgués (Rojo 2009, p. 24).

En el caso de Romilio Llanca, esas dos etapas se presentan bajo la forma de referencias al "pretérito perfecto" del protagonista. La "edad de la inocencia" estaría conformada por el período que va desde que decide salir espiritual y físicamente de su medio, Cáhuil, impulsado por el Milico, hasta que conoce a su verdadero modelo en Santiago, el carpintero anarquista llamado maestro Pascual, gracias a quien se inicia, posteriormente, en la fase del "vagabundeo programático":

Quería descansar un poco de la pelea, aunque me fui a Valparaíso a tantear cómo andaba el gremio. Pero en Valparaíso, sin saber cómo ni por qué, me vi, de un día para otro, a bordo del Vapor "Piragua", embarcado como carpintero (...) Conocí toda la costa sur de Chile, Talcahuano, Lota, Puerto Montt, Corral, Ancud, Castro, Melinka, Punta Arenas; llegué hasta Buenos Aires. En otros viajes conocí

$8 \quad$ La "edad de la inocencia y del vagabundeo programático", es representada por Manuel Rojas, a través de las obras "Laguna" (en Hombres del sur), "El vaso de leche" (en El delincuente), Lanchas en la bahía, Hijo de ladrón, Sombras contra el muro y La oscura vida radiante. Todos estos cuentos y novelas, así como este extracto de la vida de Rojas poseen, según Grínor Rojo, cierta unidad de acción y de sentido otorgada, fundamentalmente, por la figura del joven en proceso de formación, cuyo estado característico es su nomadismo, su soledad, su desamparo y su hambre física y espiritual, pero en cuyos avatares parecen encontrarse las claves acerca de la identidad del hombre adulto, de su relación con los demás, con la mujer y con la madurez que "pudiera consistir en su integración o no en el sistema de las instituciones burguesas tales como ellas son" (Rojo 2009, p. 8). 
Coquimbo, Taltal y todos los puertos del sur, del norte y del Ecuador (Rojas 1974, p. 954).

La segunda nouvelle que podemos distinguir en Punta de rieles es la "nouvelle de burgués desclasado", representada por la historia de Fernando Larraín Sanfuentes ${ }^{9}$. Temáticamente, esta nouvelle mantiene ciertas relaciones con distintos sectores de la obra de Rojas, lo que no impide que sea una verdadera novedad dentro de su universo narrativo y el elemento que le presta su singularidad a Punta de rieles como conjunto.

El primer antecedente es el recientemente mencionado tercer período de la saga de Aniceto Hevia, cuyo punto de encuentro sería el tema de "la integración burguesa frustrada", que se presenta en la historia de Fernando Larraín Sanfuentes mediante el relato de su proceso de desclasamiento, como consecuencia de su fracaso al iniciar su vida adulta, familiar y laboral. El segundo antecedente sería el cuento "La compañera de viajes", recopilado en la colección titulada El delincuente (1929). Este relato es el único texto en el universo narrativo de Rojas previo a Punta de rieles en que el autor se concentra en el retrato de personajes burgueses.

Inspirado, según Grínor Rojo (Rojo, La contra de Rojas 4), en la narrativa de salón o de club de la literatura europea del XIX (Kipling, Conrad, Somerset Maugham), el cuento relata el encuentro entre un hombre y una mujer que se conocen por causa de un problema técnico que obliga a la dama a dejar su tren ("El expreso de París") y subir en aquél más simple y barato donde viaja el caballero. El último antecedente lo encontramos en el personaje que aparece en Sombras contra el muro y que también es destacado por Grínor Rojo. Se trata de el Checo, el cual corresponde al mismo perfil de Fernando Larraín Sanfuentes: "El Checo, que es un mal sujeto, es también un hijo de "familia decente" que se salió del camino recto y "se ha corrompido", corrompiendo en el camino a las muchachitas más pobres de su barrio" (Rojo 2009, p. 20).

9 En cuanto al material que lo ayudaría a dar forma a la historia de Fernando Larraín Sanfuentes, este fue, sin duda, proporcionado por su matrimonio con Valeria López Edwards, con quien Rojas estuvo casado alrededor de veinte años antes de conocer a Julianne Clarke en Estados Unidos, el año 1961. Gracias a su relación con López Edwards, Manuel Rojas accedió no solo al conocimiento directo de ciertos modos, costumbres y valores de la clase alta chilena sino, además, se enteró de la gran mayoría de las historias que conforman el desfile de personajes secundarios de esta mitad de la novela: "Casi innecesario resulta decir que todos los incidentes de la vida de Fernando Larraín Sanfuentes son o verídicos en absoluto o basados en hechos o compuestos con hechos y personajes reales" (Rojas 1962, p. 246). 
Por último, tendríamos que referirnos a lo que aquí queremos denominar como la "nouvelle de encuentro entre mundos" que, en Punta de rieles, está constituida por la situación enunciativa que hace interactuar el soliloquio de Romilio, con el monólogo interior de Fernando Larraín. Esa situación es la que Rojas toma, casi al pie de la letra, de la historia de su amigo Julio Asmussen ${ }^{10}$ y con cuya ficcionalización reúne los dos tipos de mundos que antes se encontraban separados. La narrativa del autor chileno presenta para esta nouvelle solo un antecedente, que es el cuento "Poco sueldo", recopilado en la colección intitulada Travesía (1934). A pesar de carecer de la temática criminal y erótica tan importante en Punta de rieles, "Poco sueldo" se estructura a partir del mismo choque entre dos mundos. El de un personaje subalterno llamado Laureano, que trabaja como electricista en una empresa, con su superior, que cumple el papel de administrador de la misma. Laureano va al escritorio del administrador para hacer un trabajo de rutina, cuando de repente se le ocurre pedir un aumento de salario, a partir del cual, el administrador lo descubre por la primera vez:

El administrador levanta la cabeza:

— ¿Qué pasa? ¿No terminaste ya?

-Sí, señor, es que...

- ¿Qué?

-Yo quiero aprovechar este momento para hacerle una petición.

— ¿Cuál?

- Quisiera pedirle, señor, un aumento de sueldo. Gano tan poco aquí, señor, que apenas me alcanza para vivir mal, y tengo mujer y dos hijos. Desde hace dos años, que me aumentaron el sueldo en veinticinco pesos, no se han vuelto a acordar de mí. Y ya ve que soy electricista....

10 La historia, de 1927, es la siguiente: “Según Julio Asmussen, en la madrugada anterior, cuando había pensado cerrar el diario para marcharse a su casa, un hombre solicitó hablar con él. El director pensó en negarse, pero le dijeron que era un individuo que él conocía porque realizaba labores sindicales y había dirigido con mucho acierto una huelga importante. De manera que lo dejó pasar. Entonces sucedió lo que más tarde contaría Asmussen a Rojas y a sus amigos" (Rojas 1962, p. 235). 
- Sí. ¿Cuánto ganas tú?

- Gano cien pesos al mes. Ya ve, señor, ¿qué son cien pesos al mes para un hombre que tiene mujer e hijos?

— iCien pesos! El administrador da una mirada al obrero. Es la primera vez que lo mira detenidamente, a fondo. No tiene costumbre de mirar con detención a los trabajadores de la empresa. Los mira bien nada más que al tomarlos, para ver si son sanos, fuertes, si denotan hábitos de trabajo. Una vez colocados no los mira sino a la cara y rápidamente, al mandarlos o al saludarlos. Ignora cómo viven. No tiene tiempo de informarse. Pero esa mañana mira al hombre que tiene delante, como se debe mirar a los hombres, de arriba abajo, para saber de ellos no sólo lo que dicen o piensan, sino también lo que viven y sienten. El examen le produce angustia; aquello no es un hombre, es un estropajo. Nunca he visto tanta pobreza y tanto abandono.

-Bueno - dice mirando a otra parte-; en realidad no ganas demasiado. Pero yo me ocuparé de ti. Ahora, vete.

El hombre da las gracias y se retira, y cuando la puerta se cierra suavemente tras él, el administrador exclama:

—QQué horror!

Y sigue estudiando el contrato.

(Rojas, "Poco sueldo" en Travesía 134-135)

\section{LOS DOS MUNDOS EN ENCUENTRO}

Punta de rieles se inscribe dentro de la gran tradición de la novela de la corriente de la conciencia ${ }^{11}$. Narratológicamente, se estructura a partir de

11 El primer elemento que permite identificar una novela de la corriente de la conciencia, según Robert Humphrey, es su argumento: se trata de obras cuyo objetivo fundamental es relatar la conciencia de uno o más personajes, entendiendo por conciencia "el desarrollo completo de la reflexión mental, desde los niveles anteriores a la conciencia misma hasta los más superiores de la razón, pasando por diferentes estratos mentales e incluyendo el más alto de ellos, el del conocimiento racional comunicable. De este último generalmente se ocupa la novela sociológica. Y de este difiere la de la corriente de la conciencia, precisamente, porque trata de aquellos niveles anteriores a la verbalización racional: los niveles al margen de la reflexión" (Humphrey 1969, p.12). En este sentido, su fin fundamental es el de mostrar al hombre interno, que se encuentra bajo la superficie de la dimensión comunicativa, antes que las motivaciones o acciones del hombre externo (las cuales estarían relacionadas con el pensamiento behaviorista o positivista, y con la novela experimental). 
dos formas de discurso: el soliloquio y el monólogo interior, cada uno de los cuales es gráficamente marcado por distintos recursos tipográficos. El uso del guión anuncia el comienzo y el final del soliloquio, y el uso del paréntesis abre y clausura el monólogo interior. El primero corresponde al relato de Romilio Llanca; el segundo, al de Fernando Larraín Sanfuentes. A través de ellos, Rojas presenta, en boca de los propios personajes, las dos historias aludidas, divididas en veintitrés capítulos contrapuestos, a lo largo de los cuales el narrador interviene solo tres veces: "En el capítulo II, para introducir al carpintero, en el IX, para dirigir el monólogo de uno de los personajes y, en el último, para terminar" (Rojas 1962, p. 240). Ambos discursos, el soliloquio y el monólogo interior, se articulan en la novela mediante un montaje de espacio, situación que mantiene fijos a los personajes en un lugar, mientras sus conciencias viajan por el tiempo. Las coordenadas para realizar ese montaje son las siguientes: como se señala en el capítulo I, la novela abre a las 2:30 de la mañana, momento en que Fernando Larraín se encuentra en compañía de dos de sus trabajadores: Juanito y el personaje de sobrenombre el Mugriento. A las 3:15, según se indica en el capítulo II, aparece Romilio Llanca en la imprenta. En el capítulo VI, se señala que son las 4:00 de la madrugada y que está comenzando a amanecer, siendo el amanecer definitivo la última coordenada temporal que el autor nos ofrece. Esto significa que el encuentro que da contexto a la historia tiene una duración de aproximadamente tres horas y media, si consideramos que debe haber amanecido a las seis de la mañana. En este plano del relato, entonces, la novela sucede dentro de un número de horas deliberadamente marcadas por el autor, a partir de las cuales entraremos en el espacio y en el tiempo más amplio de los dos mundos interiores en encuentro.

El primer mundo que la novela nos presenta es el de Fernando Larraín Sanfuentes, el burgués desclasado. Según la ideología que él mismo expresa en su discurso -y que expondremos más adelante-, él es un desclasado por haber sido incapaz de incorporar los valores ligados a los nuevos sujetos sociales que provienen de las clases medias (representadas, ilustrativamente, por los "Escalante", o "escaladores") y del proletariado (Llanca), asociados al emprendimiento y a la iniciativa individual. Su figura parece ser, así, la imagen con que se simboliza una clase social en crisis, es decir, una situación colectiva de la élite de la época.

El relato de este burgués desclasado se distribuye en tres ejes espaciales. El primero de ellos corresponde al conjunto de lugares asociados a la casa paterna: el sitio del tío Eugenio, donde se inicia sexualmente; el prostíbulo 
"de segunda categoría" al que recurre sistemáticamente y donde conoce a Lía, prostituta con la que entabla su primera relación más o menos estable durante un año hasta contraer sífilis; y el banco, donde se inicia en el mundo del trabajo con el cargo de junior. El segundo eje espacial es el de su propio hogar. Este se inaugura con el matrimonio de Fernando con Clara y se rompe mediante un proceso lento de desintegración, que comienza cuando llega por la primera vez borracho a su casa; continúa con la pérdida de su empleo debido al alcohol y el abandono de su mujer y de sus hijos; y termina cuando deja el trabajo que los Escalante le habían ofrecido. Rasgada queda toda relación con el hogar, todo vínculo con el espacio de la casa, dándose inicio, así, al período del "vagabundeo marginal". Fernando se reúne, entonces, con aquello que aparece como la escoria de todas las clases sociales: cocainómanos, morfinómanos, etc., y duerme por primera vez en conventillos. Durante este período, tiene breves momentos de recuperación como, por ejemplo, cuando Alfonso le da la oportunidad de trabajar en su parcela; pero en Valparaíso recae en el alcohol. Se inaugura, entonces, el tercer espacio, correspondiente al conventillo, en que Otilia lo recibe, y que funciona como una recuperación marginal del hogar. Por el lugar en el que se encuentra, se sabe que el último espacio de la historia de este personaje es Antofagasta.

El relato de Fernando abarca alrededor de ocho años, apuntados por el comienzo de su trabajo en el banco a los dieciocho; después, por el momento en que "reconoce" al padre, a los diecinueve; más tarde, por la relación que mantiene con Lía, la prostituta; y, por último, por los cinco años que dura su matrimonio con Clara. En relación con este periodo, solo tres de esos años -marcados, a su vez, por el nacimiento de dos de sus hijos-, corresponden a cierto idilio burgués, y dos al periodo de la decadencia y de la "integración frustrada". Podría hablarse también de un último período, cuya duración no es precisada, que corresponde a su relación con Otilia, mujer de pueblo a la que deja embarazada ${ }^{12}$.

El segundo mundo que la novela presenta es el de Romilio Llanca, el carpintero sindicalista en vías de proletarización (y criminalización). Su historia posee seis ejes espaciales, que son los que apuntan su recorrido formativo. El primero de ellos es su pueblo de origen, Cáhuil, donde trabaja como cartero y de donde surge gracias a la influencia del Milico. El segundo de ellos es 
Santiago, la capital, donde conoce al maestro español y supera las limitaciones que el medio le pone: la ignorancia y el hambre, fundamentalmente. En Santiago, Llanca vive en la casa de dos de sus compañeros de servicio militar. Primero, bajo la protección del maestro Pascual; después, de manera más independiente, por algunos años, durante los cuales se reúne con otros obreros y se dedica a organizar el gremio. El tercero de los espacios es Valparaíso, donde se dirige con el fin de "sondear" el estado de la actividad gremial de esa ciudad. El cuarto es el barco Pisagua, en el cual trabaja de carpintero y donde realiza tres viajes: por la costa de Chile hasta Buenos Aires, por los puertos del norte, Perú y Ecuador. En el tercer viaje desembarca y pasa a habitar el quinto eje espacial de su formación, que se caracteriza por el paso del ámbito del mar al ámbito terrestre. Llega al puerto, después a La Ligua y, más tarde, a Taltal. Aquí se inicia, primero, en el trabajo de fábrica, después en el de la construcción y, posteriormente, en el de la minería. Finalmente, llega al espacio de las salitreras, el último al que accede Romilio y donde se dice que comienza la historia que culmina en la noche del asesinato.

Llanca permanece en tres salitreras del norte. Primero, en Santa Anita, lugar que descubre como un espacio ideal para el trabajo y para convivir con hombres solteros, y donde puede renunciar a la tan difícil vida amorosa. Más tarde, se instala en Mantos Blancos, salitrera nueva, donde conoce a Rosa, primero como mujer de Campón y después como su propia mujer-momento en que Llanca comienza a degradarse hasta matarla. En esta salitrera se frustra la primera huelga, motivo por el cual parte a Antofagasta, donde consigue trabajar en la salitrera Buena Ventura, menor que las anteriores, pero también mejor organizada y más antigua. Aquí comienza la caída de Llanca, hasta que, al retornar a Antofagasta, mata a Rosa y, esa misma noche, llega al escritorio de Fernando. En términos temporales, esta historia transcurre en aproximadamente cinco años, desde que Llanca se inicia sexualmente, a los veinticinco, hasta que mata a Rosa, momento en que no se especifica su edad.

La historia de Llanca corresponde, así -como ya hemos anunciado-, a la fase que los personajes anteriores de Rojas no llegan a concretar: la de integración amorosa y laboral. En su caso, esto es realizado dejando de lado su oficio de carpintero independiente para transformarse en obrero, sometiéndose a las actividades dictadas por la hegemonía del capitalismo y la industrialización. Este tránsito implica para él abandonar el modo de producción artesanal con el que había logrado salir de la sociedad de subsistencia, de la cual era originario, para ingresar en un modo de producción industrial. En él, como todos sabemos, el trabajador ya no crea más su propio producto para 
venderlo, sino que debe salir para vender su fuerza de trabajo, quedando sin orientación la fuerza creativa que antes empleaba practicando su oficio. El sentido liberador que el trabajo tenía para Romilio al inicio, cuando estaba enraizado en el quehacer artesanal que implicaba creatividad, inteligencia, sensibilidad y contacto con una tradición y un medio, se transforma radicalmente al insertarse en el modo de producción industrial. Allí, el trabajador debe realizar una labor maquinal que no demanda un saber intelectual y creativo, sino, únicamente, fuerza y resistencia física, y que lo obliga a desenraizarse de su tierra, entrar en un medio extraño y desvincularse de sus tradiciones.

Su historia es, por lo tanto, el caso concreto de un fenómeno más amplio que corresponde a la historia general del bajo pueblo en vías de proletarización, que fue absorbido de su condición premoderna por las condiciones alienantes del trabajo industrial, las mismas que llevan a Romilio a transformarse en un criminal. Romilio se cree capaz (y al inicio, de hecho, lo es) tanto de dar forma a su propia vida, como de intervenir en la institucionalidad del mundo, primero en el gremio, después, a través de las huelgas y del trabajo sindical. Sin embargo, la verdad es que todo su recorrido corresponde al que le traza la modernidad; específicamente, el modo de producción salitrero, a través de su propia necesidad de trabajo.

Como vimos, este proceso se inicia en Cáhuil, donde existe una sociedad de subsistencia que Llanca mira de forma despectiva: lo describe como un mundo chato, sin calles ni cines, cuyos habitantes son casi todos analfabetos. Más tarde, se integra a la inmigración campo-ciudad y se dirige a Santiago, después de lo cual Llanca pasa por un breve lapso de tiempo, que podría ser interpretado como un momento de conjunción armoniosa entre pre-modernidad y modernidad. Nos referimos a su estadía en el barco Pisagua, lugar que representa un verdadero paraíso para Romilio, porque allí lo moderno (el barco) no imposibilita ni aplasta lo pre-moderno (su trabajo como carpintero). Al contrario, parece dotarlo de un espacio exclusivo para él, y le ofrece un lugar establecido para la realización de su oficio. En eso radican las connotaciones paradisíacas que el personaje le atribuye:

Había sido un sueño de muchos años, desde que, siendo niño, veía pasar, una que otra vez, muy lejos, un barco. Nunca había visto uno de cerca y me imaginaba los disparates más grandes [...] Cuando pisé la cubierta y me llevaron a mi camarote y me dijeron que allí dormiría y trabajaría, creí que había muerto y estaba en el cielo, y que Rafael Guerrero (...) era, por lo menos, el arcángel Rafael (...) 
Era el único carpintero y eso me daba una seguridad y un orgullo muy grandes (Rojas 1974, p. 954).

Después de estar en el Pisagua, como vimos, Llanca desciende a la tierra. En términos simbólicos, esa tierra en Punta de rieles representa el espacio del trabajo, pero del trabajo basado en una estructuración trágica entre la voluntad del sujeto subalterno y la productividad industrial. Al descender del barco, Llanca abandona la armonía previa de manera progresiva, siendo prácticamente tragado por lo terrestre, pasando de una industria a otra, hasta llegar a las salitreras, antítesis del Pisagua, es decir, el infierno mismo, precisamente porque en él la armonía entre lo pre-moderno y lo moderno no es posible.

¿Pero cómo se relacionan estas dos historias: la del "roto" con la del "caballero"? Para decirlo de modo directo, observamos que este encuentro entre mundos ideado por Manuel Rojas está marcado por la ironía. Una ironía que surge como consecuencia de la representación de dos personajes que no responden al paradigma dentro del cual son presentados, sino precisamente lo contrario ${ }^{13}$. Para eso, el autor divide el relato en cuatro ejes temáticos, alrededor de los cuales cada uno de los personajes expone en contrapunto sus ideas y experiencias. En su conjunto, ellos van mostrando cómo cada uno desestabiliza su respectivo estereotipo, hasta producir la inversión final de los papeles. La consolidación de esta ironía alcanza su punto más alto con el juicio final de Larraín Sanfuentes que articula la historia, y se expresa en frases como la siguiente: "¿Qué puedo hacer por este hombre, yo, que nunca hice nada por mí?" (Rojas 1974, p. 945). O: "Viene a pedirle consejos a un

13 "La ironía verbal (tradicionalmente clasificada como un tropo) es una afirmación en que el significado que el hablante quiere transmitir difiere agudamente del significado expreso de manera ostensible. La afirmación irónica usualmente involucra la expresión explícita de una actitud o evaluación, pero con señales en la situación comunicativa como un todo de que el hablante posee una muy diferente, y habitualmente opuesta, actitud o evaluación" (Abrams 1985, p. 97, Traducción nuestra). Como veremos en las páginas siguientes, esta definición de ironía, que está particularmente presente en la novela de Rojas, es utilizada también, y sobre todo, estructuralmente, es decir, de manera que "el autor, en lugar de usar una ocasional ironía verbal, introduce un marco estructural que sirve para sostener la duplicidad de significado y evaluación a lo largo del trabajo" (Abrams 98). En el caso de Punta de rieles, dicho marco estructural corresponde a los recursos narratológicos del monólogo interior y soliloquio, que ponen en tensión y permiten ver las contradicciones entre lo que los personajes realmente son y lo que dicen. 
borracho, pensando que es un gran señor. Pucha, las cosas que se ven, es difícil de creer, pero es así" 14 .

Los capítulos 3 y 4 giran en torno al "crimen": el evidente crimen penal que corresponde al de Romilio Llanca, pero sobre todo, el crimen civil secreto de Larraín, siendo este el primer elemento de desestabilización de la figura del caballero:

¿Podría haber matado yo a la Clara? Ni curado. Si con que la mirara mal se ponía a llorar. Y tan carajo que me porté con ella. No la maté, pero lo que hice fue peor. De qué puedo admirarme. Este gallo ha matado a su mujer y es más que posible que se coma sus años de cárcel; aguantará como un hombrecito. Yo, hijito de familia, hice algo peor y estoy libre ${ }^{15}$.

Los capítulos 5, 6, 7 y 8 giran en torno del tema del “origen" y las relaciones que cada personaje tiene con él. En el caso de Fernando Larraín Sanfuentes, lo primero que él analiza son los capitales que posee la élite y los tipos de sujetos que se pueden encontrar en las clases altas, de acuerdo con el uso que estos escogen darles. El principal capital que el narrador distingue es el capital social representado por los apellidos:

Pero no toda la gallada sale igual ni las posibilidades no se las meten a uno en el bolsillo. Hay que hacer algún empeño para conseguirlas. Hay ñatos que sacan a sus apellidos todo el jugo que tienen; unos tienen más que otros. Es cuestión de saber manejar la teta. Otros no les sacan nada y les habría dado lo mismo llamarse Catrileo o Campillai. No les interesa, no tienen ñeque o son tarados. Algunos les dan más brillo del que tienen, otros les dan más plata. Otros los dejan a la altura del unto" (Rojas 1974, p. 951).

Según Larraín, los miembros de la élite se dividen de acuerdo con el uso que dan a sus apellidos, capital que puede ser administrado con distintos niveles de eficiencia. En primer lugar, están los que "le sacan todo el jugo a sus apellidos", es decir, que administran ese capital con un nivel de relativo éxito. En segundo lugar, existen los que "le sacan más brillo del que tiene" o "más dinero": no solo se benefician del apellido, sino que también lo 
mejoran. Hay, por otro lado, en la élite, sujetos que "no le sacan nada", es decir, que desperdician sus apellidos y los administran de manera ineficiente. Por último, estarían los que "lo dejan a la altura del unto", o aquellos que, no satisfechos con desperdiciar ese capital, perjudican su valor, es decir, lo empeoran. Esos diferentes modos de administrar el capital dependerán del "interés", de la "garra" o de la "inteligencia" de quien lo posea.

Fernando realiza esta conceptualización a partir de su posición de desclasado, la cual es consecuencia no de su incapacidad de producir capital monetario - pues eso no constituye causa de eliminación para la élite-, sino por haber desperdiciado su capital social -que es el capital del grupo-, "botando" la plata y "comportándose como un bruto" con los suyos. En otras palabras, Larraín es desclasado de su grupo sobre todo por haber perdido la honra, no respondiendo por sus actos frente a su familia, y traicionando a quienes lo apoyaron y confiaron en él (fundamentalmente, los Valdivieso y los Escalante). Utilizando las categorías aportadas por su propio discurso, su caso forma parte, por lo tanto, de aquellos que por "falta de garra" dejaron su capital social "a la altura del unto", desperdiciándolo y empeorándolo.

Por detrás de su desclasamiento hay, así, algo que parece estar más allá del capital social, y que depende, en última instancia, del valor personal. En este sentido, al contrario de lo que Fernando piensa, más que el daño a su apellido, la causa de su desclasamiento parece haber sido, sobre todo, su modo de comprender su propia posición social y la de sus iguales. Este modo se caracteriza por la desvalorización de los méritos individuales y por la sobrevaloración de las expectativas que él tiene sobre los capitales básicos de su clase.

De hecho, la historia de formación de Larraín consiste en el desarrollo de una vida en que la iniciativa personal tiene un valor prácticamente nulo, en comparación con las prácticas casi rituales que él describe como propias de su medio. Estas son: perder la virginidad con las trabajadoras de la hacienda, casarse con el modelo de mujer casta, sumisa y virginal, al que corresponde Clara. Y, por último, trabajar de junior en un banco, como estrategia para simplemente esperar el soñado cargo de gerente o subgerente que la clase le promete ${ }^{16}$. En suma, una concepción casi burocrática de la existencia, donde

16 "Hay que comenzar de alguna manera: la primera hembra, una china; la segunda, una puta; primer empleo, junior" (Ibíd., p. 964). 
el sujeto no da forma a su propia vida, sino que recibe la que le entrega su medio, esperando que se cumplan los designios de su clase:

Empecé a trabajar para tener dinero con que acostarme con las chuscas; seguí trabajando porque estaba casado e iba a tener hijos. Alguna vez llegaría a ser gerente o subgerente, jefe de algo por lo menos, aunque muchos esperaban lo mismo [...] Lo que me faltaba era poder quedarme tranquilo en algo y en alguna parte. Me gusta el cambio, sobre todo el cambio repentón y fuerte. Tal vez por eso me gustó el trago... (Rojas 1974, p. 978).

Al contrario, la formación de Romilio hasta antes de su caída final responde a una concepción general de la vida como despliegue, lo que se manifiesta en el tipo de vínculo que este mantiene con su medio de origen, en la visión que desenvuelve y materializa con respecto al trabajo y a la política, y en el modo como concibe el amor.

Romilio encuentra en ese recorrido dos modelos: el Milico y el maestro Pascual. El primero de ellos le enseña a trabajar por la primera vez y despierta en él el deseo de salir del pueblo, pero sin llegar a transmitirle lo que para Llanca constituía el "verdadero trabajo" y la verdadera trayectoria existencial. El Milico le enseña a "a aserruchar todo al ojo y a la sin rumbo, marcando los cortes de un clavo" 17 y a salir del pueblo siguiendo el camino de la carrera militar. El verdadero modelo de Llanca, por lo tanto, no será el Milico, sino el maestro Pascual, a quien buscará definitivamente imitar, y cuyo pensamiento coincidirá con su noción expansiva de la existencia. El maestro Pascual le enseña a Romilio lo que él comprende como el verdadero trabajo. Además, lo pone contacto con las ideas anarquistas y lo empuja a una vida de lucha e itinerancia. Gracias a la influencia del maestro Pascual, el concepto de trabajo que Llanca va adquiriendo y poniendo en práctica es el del trabajo como oficio, lo que implica conocimiento, método, creatividad y, junto con eso, un desdoblarse del individuo en el ámbito de lo público. Será en defensa de estas ideas que el personaje definirá el tipo de lucha política que le interesa:

Me interesa la pelea en los gremios, sin el ánimo de cambiar la sociedad, como quieren los anarcos, ni de reemplazar a los patrones en el manejo de la cosa, como quieren los socialistas y comunistas 
(...) Me juré que nunca sería más que obrero. Nada de ser contratista o patrón. Dejaría de ser lo que me gusta (Rojas 1974, p. 953).

Romilio defiende la lucha gremial, porque ella se presenta no como búsqueda de poder, sino como una organización de trabajadores cuya finalidad primera es la cautela del oficio. Para Romilio, lo más importante es realizarse como artesano. Buscar poder, como él observa que sucede con algunos sindicalistas, o con aquellos que aspiran a ser "patrones" o "contratistas", sería dejar de hacer lo que para él es lo más importante: trabajar, practicar un oficio que encarne ese concepto general de la vida como despliegue. Romilio quiere realizarse y esa realización se opone al juego de ser controlado y controlar. Controlar es ejercer la voluntad, no es despliegue de sí porque el sujeto no es pura voluntad, ni pura vocación de control. Ser controlado tampoco es despliegue, porque, en este caso, siempre habrá uno que se somete a la voluntad de otro:

La verdad es que nunca me he podido explicar porqué o cómo un hombre puede tener tantas ganas o tanta aspiración de mandar, de tener el palo en la mano, de ser el jefe. Tampoco me he podido explicar porqué los más ambiciosos de poder son los que menos valen, en tanto que los que más valen no se interesan por mandar ${ }^{18}$.

Del capítulo 9 al 16, "la sexualidad" es el tema predominante. Mientras Larraín reduce el sexo a una práctica depredadora que él ejerce, principalmente, con las prostitutas, para Llanca la sexualidad será vista como una expresión de la naturaleza, siendo indisociable del amor y de la ternura, que él siente, incluso, por las prostitutas con que se inicia. Por otro lado, según Llanca, el amor es inseparable de sus intereses políticos. Para él, lo privado -la intimidad-, es más comprensivo que lo público, pues este es el lugar donde el sujeto se expone por entero, incluyendo sus ideas y sus intereses ligados al trabajo. De modo que, si en lo público no se comparte lo privado, en lo privado sí debe compartirse lo público:

Cuando le hablé de mis ideas me miró como si estuviera curado y cuando intenté explicarle por qué pasaban algunos hechos, las huelgas, las revoluciones, por ejemplo, se quedó dormida. "No me hable de 
esas patillas. No entiendo nada. Dígame mejor qué va a hacer si nos echan de aquí" 19 .

Finalmente, los capítulos que van del 17 al 22 se refieren a "la caída", tópico mediante el cual el autor parece querer hermanar las experiencias de Llanca y de Larraín. Así, lo que el libro parece sugerir es que tanto uno como el otro caen por vivir insertos en un sistema económico que actúa sobre ellos de manera idéntica: atacando sus debilidades, es decir, aquellos puntos que están fuera del ámbito del aprendizaje.

En el caso de Llanca, su caída se produce por motivos distintos que abarcan la totalidad de su persona. Sin embargo, su flaqueza en el plano amoroso será como la puerta de acceso para que todos los planos de su existencia colapsen, precipitando su desintegración. Estos son: el plano del trabajo, el plano de la política y, por último, el propio plano amoroso, a partir del cual se inicia la caída. De hecho, el recorrido total de Romilio puede ser comprendido como el tránsito de una estado de organicidad, en que él desarrolla las capacidades relativas a estos tres niveles, a un segundo estado que podemos caracterizar como de embrutecimiento, alienación, humillación y artificialidad que consiste, precisamente, en la frustración de los ideales que los articulaban.

En lo que se refiere al trabajo, es arrastrado de la producción artesanal al ámbito de las salitreras, actividad que no exige el conocimiento de un oficio y que, por lo tanto, es una especie de "no trabajo" para Llanca. En el plano político, la frustración se refleja principalmente en el movimiento huelguístico que envuelve la situación enunciativa de la narración y en la huelga frustrada a la que se hace referencia en el capítulo XVIII. Como un salto de lo individual a lo colectivo, mediante esas huelgas se percibe que el trabajador no está siendo capaz de ejercer su voluntad al interior de las salitreras. Eso afecta especialmente la realidad de Romilio, si consideramos que el ámbito de lo público y de lo político constituye la dimensión más fuerte de su personalidad y la única en la que realmente desdobla su carácter, pues ella le permite materializar su altruismo, es decir, su vocación por las causas que son, al mismo tiempo, personales y colectivas.

La pérdida de un campo para el altruismo que se hace visible en la situación individual de Llanca, pero que es generalizable a todo el conjunto de trabajadores, produce la muerte del sentido épico de este grupo social y, 
por lo tanto, la aceptación pasiva de las nuevas condiciones de trabajo que las clases dominantes le imponen: "La huelga se fue al hoyo. Aparecieron los que hablan según Engels y según Marx; pelearon los que hablan como se puede, flaquearon unos, se aburrieron los otros y la gente volvió al trabajo casi antes de que el sindicato aceptara lo que la empresa ofreció" (Rojas 1974, p. 1003).

Por último, los ideales amorosos se frustran en la historia de Romilio con Rosa que, como fue dicho, acaba en el homicidio. Rosa lo obliga a entrar en la dinámica de la explotación, separando las dimensiones afectivas y sexuales ("No tenía idea de lo que era cariño, de lo que era ternura" ${ }^{20}$ ), lo cual lo conduce -usando una metáfora vinculada al trabajo industrial que está ejerciendo-, a representarse a sí mismo como una máquina embrutecida: "Tenía la manía de hacer el amor una y otra vez y no había nada que la detuviera. El ser humano es una máquina, como dicen algunos, pero no es una máquina que pueda hacer la misma cosa; tiene que hacer varias, sino se embrutece" (Rojas 1974, p. 1145). Este embrutecimiento se produce en Romilio no solo por la demanda sexual de Rosa, sino también por la experiencia de estar él mismo ahogado en una intimidad que no le permite un despliegue psicológico, ya que no puede hacer participar a su mujer de la vida pública. Frente a esta relación empobrecida que ella le ofrece a Romilio -comparable con la explotación que está padeciendo el personaje en las salitreras-, la experiencia amorosa lleva al hombre hacia una dirección totalmente opuesta a la realización de sí. Lo conduce, como él mismo dice, al embrutecimiento, empequeñecimiento y, finalmente, a la humillación que el crimen final representa. En este marco, Llanca aspirará sin éxito a dominar a Rosa, no para explotarla, sino para desdoblar los atributos que son propios de la masculinidad, es decir, para poder cumplir con su propia naturaleza y, por lo tanto, con su libertad originaria:

Soñaba, había soñado a veces, con noches así, interminables. En esas noches, sin embargo, el jinete era yo. En la noche pasada no había sido más que el jineteado. Bueno, bien pudiera ocurrir que fuese yo el que después pasara a mandar el buque, el que lograra por fin ser el dominante ${ }^{21}$. 
El punto débil de Larraín es su falta de disposición para el trabajo, carencia que parece sustituir por el alcohol, causa principal de su caída, y también, de los otros dos hombres de la familia: su padre y su hermano Federico. Fernando (y todos los hombres que lo rodean) no valora el trabajo como Llanca, que organiza toda su vida en torno del deseo de desdoblar su oficio como carpintero. Esto se evidencia en su opción estratégica de trabajar como junior en un banco, pero sobre todo, en los recuerdos intercalados que el autor integra dentro del discurso de Fernando: "Qué hubo, Fernando, te volviste a quedar dormido." "Puchas, otra vez llegó usted. Ni dormir lo dejan a uno." "Pero, hijito, sólo te quedan veinte minutos para llegar al banco". "Qué va a decir el tío Chalo, ¿verdad, mamá? Bueno, ya está. Me voy a levantar. Arriba"22.

Ya que Fernando y todos los hombres de su familia reposan sobre los valores tradicionales basados en la herencia de capital social y monetario, ellos desvalorizan el trabajo, cuya ausencia y vacío parece ser sustituido por la bebida, elemento corrosivo que los lleva a la decadencia. Dentro de este proceso, la mujer de élite ocupa un lugar capital. De hecho, las pocas referencias a los personajes femeninos que aparecen en el libro están asociadas al control que ellas tienen sobre la relación de sus hombres con el alcohol. Tanto la madre de Fernando, como Clara, su mujer, se presentan, cada una a su manera, como mujeres totalmente condescendientes con el alcoholismo de sus maridos, mostrando una total incapacidad de cooperar con su inserción social. Dice Fernando sobre Clara: "No me hizo ninguna censura. Me recibió más suave y más tierna que nunca" (Rojas 1974, p. 987). Tal actitud contrasta con la que mantienen las mujeres populares con que Fernando se relaciona. Trátase de mujeres que saben poner un freno en sus hombres, pues, vulnerables socialmente, no pueden permitir que sus maridos caigan en ese vicio que debilita la voluntad de trabajar, único soporte del que disponen. En las últimas escenas de la novela, Otilia aparece expresamente protegiendo a Fernando del alcohol:

La Otilia me consiguió no sé dónde un pollo más o menos flacón y ellos se prepararon un buen pescado. Don Víctor llegó con una buena botella de vino. Me la quedé mirando y cuando la destaparon y el maestro hizo ademán de llenar las copas, yo alcancé la mía. "No, usted no", dijo inesperadamente Otilia, apartando mi copa de 
la botella. “¿Por qué no?”, pregunté asombrado. Era la primera vez que alguien me decía que no bebiera una copa de vino ${ }^{23}$.

La ironía se establece, así, de forma definitiva. La distinción entre la historia del "roto" y la del "caballero", inicialmente basada en criterios asociados al origen social y familiar de los personajes, es desestabilizada a partir de nuevos parámetros vinculados al uso que cada uno de ellos hace de sus capitales. De esta perspectiva, el "caballero" al que Romilio se aproxima para que juzgue sus actos va lentamente transformándose a los ojos del lector en lo que, a partir de sus propias afirmaciones, corresponde a un "no caballero", es decir, a un "roto". Un "roto" que desperdició su capital social, transformándose en un borracho, y abandonando a su mujer sin después tener la "honra" de responsabilizarse por lo hecho. Lo que sucede con Llanca es precisamente lo opuesto. Romilio saca un provecho milagroso de los pocos capitales con los que cuenta, transformándose en el único personaje verdaderamente activo dentro de la novela. Y, lo que es más importante, además tiene la "honra" (el valor, el coraje) de presentarse frente a Fernando para confesarle su crimen. De "roto" y de "asesino", Romilio se transforma en el "caballero" de la novela.

La relación que se establece entre Fernando y Romilio es entonces irónica. Romilio, el verdadero caballero de la historia, se aproxima a Fernando porque ve en él una autoridad que lo podrá juzgar a partir de su privilegiada y respetable posición. Al contrario, ese "caballero" es un "roto", que lo juzga de una posición que realmente no tiene, pero apelando a sus códigos: los códigos de la honra y del capital social.

De hecho, ¿qué es lo que Fernando le recomienda y promete a Romilio? Primero, le sugiere entregarse a la policía; después, promete "ayudarlo". En otras palabras: lo orienta a continuar haciendo aquello que él mismo no fue capaz de hacer, es decir, actuar con "honor". Estas sentencias funcionan también de manera irónica: un deshonrado y un desclasado apela a la honra y a su clase para aconsejar y juzgar a otro que aprovechó los mínimos que la vida le ofreció y que está allí, precisamente, para responsabilizarse por sus errores.

A pesar de contar con la posibilidad de recurrir a una ley subjetiva basada en la empatía, Fernando apela, mediante su decisión, a una ley que él considera objetiva, pues la ha sufrido en carne propia. Durante todo el relato, Larraín 
establece puntos de unión entre sí mismo y Romilio: se compara con él, se evalúa a partir de él y, en cierto sentido, establece una relación de empatía con él. Sin embargo, como la narración le va recordando su propia historia, finalmente toma la decisión de abandonar tal empatía, proponiéndole al trabajador lo que habría sido más correcto para sí mismo: conservar la "honra" a costa de su libertad.

Esa decisión adquiere una especial y, podríamos decir, cruel significación, si consideramos que lo que Fernando está haciendo con Romilio al enviarlo (cariñosamente) a la prisión es excluirlo de su marginalidad, es decir, del lugar que, por definición era el lugar de lo que no podía excluir. De esa manera, al enviarlo a la cárcel, le extirpa el mínimo con que el personaje tendría la posibilidad de continuar perteneciendo a su precario medio social. Lo marginaliza de la marginalidad, lo "desclasa", es decir, le aplica a Llanca la sanción que la clase alta le aplicó a sí mismo. En lugar de resguardar el mérito de Romilio, resguarda su honra, es decir, lo protege de cometer lo que falsamente reconoce como su propio error: fallar en la honra y no en el mérito.

Esa decisión encuentra su opuesto en la actitud liberadora que el pueblo -representado por Otilia-, tiene con Larraín. De los dos únicos requisitos necesarios para ser acogido por ese pueblo -la libertad y la vida-, Otilia preserva de Fernando no solo el primero, sino también el segundo: la vida, que Fernando pone riesgo durante sus noches de farra. Salvándolo de la muerte, cumple con todo lo necesario para ser incluido.

Para terminar, nos gustaría hacer algunas consideraciones sobre el modo en que estas contradicciones se imprimen en la forma de Punta de rieles. Como dijimos al inicio de este trabajo, la novela dialoga con un hecho específico de este período histórico, relacionado con la reformulación de las relaciones entre las diferentes clases sociales que está en curso, específicamente, durante la década de 1930. Sin embargo, al mismo tiempo, ella también da cuenta de la permanencia de las relaciones de clase tradicionales, fundamentalmente, las relaciones entre la élite y el proletariado. En el libro entran en conflicto, así, dos tendencias, una "revolucionaria" y otra "conservadora", las cuales se reflejan en el uso que Manuel Rojas da a la novela de la corriente de la conciencia. La primera tendencia se hace visible en el desplazamiento que sufre, en Punta de rieles, la figura de ese narrador burgués, personalizado, que es quien da sentido a la historia y a la narración. En la novela de Rojas, él se despersonaliza y toma el lugar de un personaje más silenciado, por lo demás, mediante el monólogo interior que pone su discurso entre paréntesis. Simultáneamente, se cede la palabra oral -mediante el soliloquio-, a 
otro miembro del espectro social. Hay, por lo tanto, una cierta tendencia democratizante en la forma del texto, que se refleja en la apropiación y en la objetivación de los discursos de los distintos actores de la novela.

Sin embargo, esta misma estructuración narrativa que adquiere la obra de Rojas puede ser comprendida de un punto de vista totalmente opuesto. El soliloquio, además de "poder" implica vulnerabilidad, frente al discurso silencioso - del monólogo interior-de Fernando Larraín que, al esconder los contenidos de su mente, resguarda la autoridad que posee frente al proletario. En otras palabras, Llanca se expone frente a Larraín, pero no Larraín frente a Llanca, quien, por eso, continúa reconociendo al "desclasado" como una autoridad, perpetuando, sin querer, las relaciones tradicionales. En este sentido, la figura del burgués parece reclamar un reposicionamiento, una recuperación de su papel de donador de sentido a la historia, lo cual se ve ferozmente ilustrado en la decisión de sugerirle a Llanca entregarse a la ley, apelando, inconscientemente, a la ley de la honra y del capital social.

Tal como dijimos, el contexto histórico que ficcionaliza la novela corresponde a un momento de crisis que, en importante medida, pone fin al sistema de producción que había predominado desde fines del siglo XIX hasta la Gran Depresión: el sistema de exportaciones basado en el salitre. En este sentido, Punta de rieles puede ser comprendida como un cuestionamiento sobre las relaciones entre la élite y la clase proletaria, durante todo este ciclo del sistema económico de Chile. Frente a él, la novela ofrece una respuesta escéptica, en que el autor parece sugerir que, a pesar de la desintegración de ambos sectores sociales, el "encuentro" y las relaciones entre ambos continuarán respondiendo al mismo y originario sistema tradicional inicial, mantenido, por lo demás, por las élites. Este sería un sistema de relaciones meramente asistencialista, que provisoriamente apoya los sectores vulnerables del país, pero que no contribuye para su integración real dentro de la ciudadanía. Frente a esta realidad, la única forma de encuentro que Rojas vislumbra como posible sería un encuentro en la disfuncionalidad, en la calle, o en la prisión, espacios que asedian a ambos personajes al final del relato: a Larraín, en la posibilidad de reincidir en el alcohol, y a Llanca, mediante la inminencia de la prisión. 


\section{BIBLIOGRAFÍA}

Abrams, M. H. Dictionary of literary terms. Fort Worth: Harcourt Brace Hanover, 1985.

Bethel, Leslie, ed. Historia de América Latina. Barcelona: Editorial Crítica, 1990.

De Ramón, Armando. Historia de Chile. Desde la invasión incaica hasta nuestros días. Santiago: Catalonia, 2003.

Humphrey, Robert. La corriente de la conciencia en la novela moderna. Un estudio de James Joyce, Virginia Woolf, Dorothy, Richardson, William Faulkner y otros, Santiago de Chile: Editorial Universitaria, 1969.

Kontje, Todd. The German Bildungsroman: History of a National Genre. Columbia: Camdem House, 1993.

Rojas, Manuel. Punta de rieles, en: Obras escogidas. Vol. II. Santiago de Chile: Zig-Zag, 1974. De la poesía a la revolución. Santiago: Ercilla, 1938. Antología autobiográfica. Santiago de Chile: LOM, 1962. Travesia. Santiago de Chile: Editorial Nascimento, 1973, pp. 133-134.

Rojo, Grínor. "La contrabildungsroman de Rojas". Revista Chilena de Literatura, Sección Miscelánea, noviembre 2009. 